\title{
Standardization of Seedling Selection Criteria in Cocoa (Theobroma cacao L.)
}

\author{
P. Janani*, N. Kumar and V. Jegadeeswari
}

Department of Spices and Plantation Crops, Horticultural College and Research Institute, Tamil Nadu Agricultural University, Coimbatore-641003, Tamil Nadu, India

*Corresponding author

\section{A B S T R A C T}

\section{Keywords \\ Cocoa, Seedling selection, Nursery \\ Article Info \\ Accepted: \\ 10 November 2018 \\ Available Online: \\ 10 December 2018}

In cocoa, four yielding categories viz., ['Low' (<1 kg), 'Medium' (1-2 kg), 'High' (2-3 kg), 'Very high' (>3.0 kg)] were evaluated for standardization of seedling selection criteria at nursery stage. The results showed that the highest germination percentage, seedling height, girth, number of leaves, leaf area and seedling vigour were registered in high and very high yielding categories compared to other yielding categories.

\section{Introduction}

Cocoa (Theobroma cacao L.) is a highly cross-pollinated and heterozygous crop, the seedling progenies exhibit higher variability ( $\mathrm{N}^{\prime} G$ Goran et al., 2000). The seed is the cheapest and simplest propagule of cocoa, which is available in large quantity and give a convenient growth habit. Propagation through seedlings normally produces wide variability in their progenies. In perennial crop like cocoa, the selection of planting material is very important to perpetuate healthy, high yielding and quality plants. In a similar crosspollinated perennial seed propagated crops like coconut and arecanut attempts by earlier workers (Liyanage, 1953; Sahasranaman, 1962; Bhagavan and Nair, 1989) resulted in the standardization of criteria for selection of mother palms and selection of seedlings in the nursery based on the certain morphological traits, which are likely to produce quality and high yielding seedlings. Ascenso and Bartley (1966) suggested seedling selection criteria for cocoa could be applied in the early stage of plant development as it would be valuable in saving time and land. No earlier attempt was made in cocoa in these aspects and hence the present study was undertaken to evaluate the different groups of progenies based on mother plants yield to standardize the pre-selection criteria in the seedlings itself in cocoa. 


\section{Materials and Methods}

In Tamil Nadu Agricultural University, the survey was made in Anaimalai region of Coimbatore during 2008-2012 and 151 trees were identified (Thondaiman, 2011) based on yield, pod and bean characters. The trees were classified based on dry bean yield $(\mathrm{kg}) /$ tree as 'Low' ( $<1 \mathrm{~kg})$, 'Medium' (1-2 kg), 'High' $(2-3 \mathrm{~kg})$, 'Very high' (> $3.0 \mathrm{~kg})$ yielding categories. The mature Forastero type pods were collected in different categories and from each category, eight pods showing yellow color particularly in furrows were harvested. The pooled seeds from each category were sown in black polythene bags of 6"x 9" size and 250 gauge thickness with 4 drainage holes filled with a potting mixture of 2:1:1 proportion of Soil: Sand: FYM. The seeds were sown at a depth of $1 \mathrm{~cm}$. The experiment was laid out in completely randomized design with five replications and 200 seedlings per treatment were raised in the nursery at Anaimalai, Coimbatore, Tamil Nadu for evaluation. The germination percentage and seedling growth characters such as height $(\mathrm{cm})$, girth $(\mathrm{cm})$ and number of leaves were recorded at fortnightly intervals starting from $30^{\text {th }}$ day to $150^{\text {th }}$ days after germination. Intermodal length $(\mathrm{cm})$ was calculated at $90^{\text {th }}$ and $150^{\text {th }}$ day after germination. The length and breadth of the standard leaf $\left(6^{\text {th }}\right.$ leaf from top) were measured in 5 randomly plants in each replication and the average was calculated. The leaf area was estimated as its length multiplied by its maximum width multiplied by $0.666+0.73$ (cocoa leaf calibration factor) suggested by Bismark (2011) and expressed in $\mathrm{cm}^{2}$.

Leaf Area $=\mathrm{L} \times \mathrm{B} \times 0.666+0.73$

$\mathrm{L}$ - Length of the leaf

B - Breadth of the leaf
The vigor of cocoa seedlings was calculated by multiplying the height and stem diameter suggested by Amma et al., (2002).

$\mathrm{HD}^{2}=$ Height $\mathrm{x}(\text { Stem Diameter })^{2}$.

The data collected were subjected to statistical analysis for their significance (Panse and Sukhatme, 1967)

\section{Results and Discussion}

In the present investigation, seeds were collected from 4 different categories of mother trees based on dry bean yield such as 'low', 'medium', 'high' and 'very high' $(<1,1-2,2-3$ and $>3 \mathrm{~kg}$ dry beans per tree respectively) and the seeds were collected from each category separately and evaluated for growth parameters.

\section{Germination percentage (\%)}

The seed germination percentage of different yielding categories is presented in Figure 1. The results revealed that seedlings from high, very high and medium yielding categories invariably exhibited higher germination percentage ( 86,80 and 82 per cent) than low yielding categories (62 per cent). Amma et al., (2002) reported that the speed of germination had no significant association with final seedling vigour in hybrid cocoa seedlings. However, in coconut, Liyanage and Abeywardena (1957) suggested early germination is associated with higher yield in the adult palms and Ananda et al., (2008) observed that arecanut seedlings from early and high initial germination produced significantly more vigorous than seedlings from delayed germination.

\section{Seedling height $(\mathrm{cm})$ and girth $(\mathrm{cm})$}

The seedling height recorded at a monthly interval from one month after sowing till 
5 months showed significant differences among the different categories of seedlings from $3^{\text {rd }}$ month onwards. During $5^{\text {th }}$ month after sowing, the significantly superior seedling height was recorded in very high yielding category $(37.10 \mathrm{~cm})$ while the lowest was recorded in low yielding category (26.36 $\mathrm{cm})$. In general, seedling height increased with increasing the level of categories of seeds; very high categories registering as high as $25.08 \mathrm{~cm}$ of mean seedling height (Table 1). Significant differences with respect to seedling girth (Table 2) were recorded up to four months after sowing. The high and very high yielding categories registered more seedling girth $(2.18 \mathrm{~cm}$ and $2.15 \mathrm{~cm}$ respectively) than low yielding category (1.81 $\mathrm{cm}$ ) at all the stages of growth (Table 2).

\section{Number of leaves and Leaf area $\left(\mathrm{cm}^{2}\right)$}

The effect of different yielding categories on a number of leaves of cocoa seedlings was presented in Table 3. At four and fifth months after sowing, high yielding categories was significantly different from the other treatments having $15.12\left(4^{\text {th }}\right.$ month $)$ and 17.80 $\left(5^{\text {th }}\right.$ month) leaves per plant followed by very high yielding categories with $14.73 \quad\left(4^{\text {th }}\right.$ month) and 16.60 ( $5^{\text {th }}$ month) leaves while low yielding categories had the lowest value of 11.96 ( $4^{\text {th }}$ month) and 13.20 (5 $5^{\text {th }}$ month) leaves. Invariably the mean number of leaves in the seedlings was very high in high (10.45) and very high (10.35) categories and the low category registered the least number (8.66) of leaves. Perusal of data (Table 4) revealed that leaf area parameter failed to attain the level of significance at early stage of observations (up to 3 months). However, at later stages the differences gain statistical significance. Very high $\left(98.26 \mathrm{~cm}^{2}\right)$ category followed by high (93.61 $\left.\mathrm{cm}^{2}\right)$, medium $\left(83.89 \mathrm{~cm}^{2}\right)$ and low $\left(72.13 \mathrm{~cm}^{2}\right)$ yielding categories recorded highest leaf area per seedlings at different stages of growth.

\section{Internodal length $(\mathbf{c m})$}

The effect of different yielding categories on internodal length of cocoa seedlings was shown in Table 4. Very high yielding categories registered longest internodal length $(3.13 \mathrm{~cm})$ followed by high $(2.62 \mathrm{~cm})$, medium $(2.44 \mathrm{~cm})$ and low $(2.20 \mathrm{~cm})$ yielding categories in order.

Table.1 Seedling height $(\mathrm{cm})$ at monthly intervals in different seedling categories

\begin{tabular}{|c|c|c|c|c|c|c|}
\hline \multirow{2}{*}{$\begin{array}{c}\text { Yield } \\
\text { Category }\end{array}$} & \multicolumn{6}{|c|}{ Seedlings height $(\mathrm{cm})$} \\
\hline & $\begin{array}{c}1 \\
\text { MAS }\end{array}$ & $\begin{array}{c}2 \\
\text { MAS }\end{array}$ & $\begin{array}{c}3 \\
\text { MAS }\end{array}$ & $\begin{array}{c}4 \\
\text { MAS }\end{array}$ & $\begin{array}{c}5 \\
\text { MAS }\end{array}$ & Mean \\
\hline Low & 14.19 & 16.55 & 19.74 & 23.59 & 26.36 & 20.08 \\
\hline Medium & 14.29 & 17.09 & 21.98 & 25.93 & 31.54 & 22.16 \\
\hline High & 14.51 & 17.44 & 25.59 & 32.29 & 35.22 & 25.01 \\
\hline Very high & 14.46 & 18.72 & 24.81 & 30.33 & 37.10 & 25.08 \\
\hline Mean & 14.36 & 17.45 & 23.03 & 28.03 & 32.55 & \\
\hline $\mathrm{SE}(\mathrm{d})$ & 0.82 & 0.74 & 1.14 & 1.07 & 0.96 & \\
\hline $\begin{array}{c}\mathrm{CD} \\
(\mathrm{P}=0.05)\end{array}$ & NS & NS & $2.42 * *$ & $2.27 * *$ & $2.04 * *$ & \\
\hline
\end{tabular}

MAS- Months After Sowing 
Table.2 Seedling girth $(\mathrm{cm})$ at monthly intervals in different seedling categories

\begin{tabular}{|c|c|c|c|c|c|c|}
\hline \multirow{2}{*}{$\begin{array}{c}\text { Yield } \\
\text { Category }\end{array}$} & \multicolumn{6}{|c|}{ Seedling girth $(\mathrm{cm})$} \\
\hline & $\begin{array}{c}1 \\
\text { MAS }\end{array}$ & $\begin{array}{c}2 \\
\text { MAS }\end{array}$ & $\begin{array}{c}3 \\
\text { MAS }\end{array}$ & $\begin{array}{c}4 \\
\text { MAS }\end{array}$ & $\begin{array}{c}5 \\
\text { MAS }\end{array}$ & Mean \\
\hline Low & 0.94 & 1.41 & 1.75 & 2.14 & 2.82 & 1.81 \\
\hline Medium & 1.12 & 1.54 & 1.91 & 2.39 & 3.00 & 1.99 \\
\hline High & 1.34 & 1.69 & 2.15 & 2.58 & 3.15 & 2.18 \\
\hline Very high & 1.27 & 1.68 & 2.07 & 2.68 & 3.07 & 2.15 \\
\hline Mean & 1.16 & 1.58 & 1.97 & 2.45 & 3.01 & \\
\hline $\mathrm{SE}(\mathrm{d})$ & 0.10 & 0.07 & 0.10 & 0.06 & 0.15 & \\
\hline $\begin{array}{c}C D \\
(P=0.05)\end{array}$ & $0.22 * *$ & $0.15^{* *}$ & $0.22 * *$ & $0.13 * *$ & NS & \\
\hline \multicolumn{7}{|c|}{ NS- Non Significant, " Significant, ${ }^{* *}$ Highly Significant } \\
\hline
\end{tabular}

MAS- Months After Sowing

Table.3 Number of leaves at monthly intervals in different seedling categories

\begin{tabular}{|c|c|c|c|c|c|c|}
\hline \multirow{2}{*}{$\begin{array}{c}\text { Yield } \\
\text { Category }\end{array}$} & \multicolumn{6}{|c|}{ Number of Leaves } \\
\hline & $\begin{array}{c}1 \\
\text { MAS }\end{array}$ & $\begin{array}{c}2 \\
\text { MAS }\end{array}$ & $\begin{array}{c}3 \\
\text { MAS }\end{array}$ & $\begin{array}{c}4 \\
\text { MAS }\end{array}$ & $\begin{array}{c}5 \\
\text { MAS }\end{array}$ & Mean \\
\hline Low & 4.40 & 5.27 & 8.46 & 11.96 & 13.20 & 8.66 \\
\hline Medium & 4.61 & 5.47 & 9.88 & 12.20 & 15.20 & 9.47 \\
\hline High & 4.60 & 5.58 & 9.13 & 15.12 & 17.80 & 10.45 \\
\hline Very high & 4.70 & 5.89 & 9.82 & 14.73 & 16.60 & 10.35 \\
\hline Mean & 4.58 & 5.55 & 9.32 & 13.50 & 15.70 & \\
\hline $\mathrm{SE}(\mathrm{d})$ & 0.32 & 0.26 & 0.76 & 0.83 & 0.86 & \\
\hline $\begin{array}{c}\mathrm{CD} \\
(\mathrm{P}=0.05)\end{array}$ & NS & NS & NS & $1.76^{* *}$ & $1.82 * *$ & \\
\hline NS- Non Sigr &,${ }^{*} \mathrm{Sig}$ & Highly & & & & \\
\hline
\end{tabular}

MAS- Months After Sowing 
Table.4 Internodal length $(\mathrm{cm})$ and leaf area per seedling $\left(\mathrm{cm}^{2}\right)$ at monthly intervals in different seedling categories

\begin{tabular}{|c|c|c|c|c|c|c|c|c|}
\hline \multirow{2}{*}{$\begin{array}{c}\text { Yield } \\
\text { Category }\end{array}$} & \multicolumn{4}{|c|}{ Internodal length $(\mathrm{cm})$} & \multicolumn{4}{|c|}{ Leaf area per seedling $\left(\mathrm{cm}^{2}\right)$} \\
\hline & $\begin{array}{c}3 \\
\text { MAS }\end{array}$ & $\begin{array}{c}4 \\
\text { MAS }\end{array}$ & $\begin{array}{c}5 \\
\text { MAS }\end{array}$ & Mean & $\begin{array}{c}3 \\
\text { MAS }\end{array}$ & $\begin{array}{c}4 \\
\text { MAS }\end{array}$ & $\begin{array}{c}5 \\
\text { MAS }\end{array}$ & Mean \\
\hline Low & 1.65 & 2.38 & 2.58 & 2.20 & 54.17 & 64.18 & 98.03 & 72.13 \\
\hline Medium & 2.16 & 2.54 & 2.63 & 2.44 & 62.50 & 79.71 & 109.45 & 83.89 \\
\hline High & 2.43 & 2.64 & 2.80 & 2.62 & 64.25 & 90.20 & 126.39 & 93.61 \\
\hline $\begin{array}{l}\text { Very } \\
\text { high }\end{array}$ & 2.77 & 3.18 & 3.45 & 3.13 & 68.19 & 99.27 & 127.32 & 98.26 \\
\hline Mean & 2.25 & 2.68 & 2.86 & & 62.27 & 83.34 & 115.29 & \\
\hline $\mathrm{SE}(\mathrm{d})$ & 0.16 & 0.16 & 0.15 & & 5.22 & 7.18 & 4.65 & \\
\hline $\begin{array}{c}\mathrm{CD} \\
(\mathrm{P}=0.05)\end{array}$ & $0.34 * *$ & $0.35 * *$ & $0.31 * *$ & & NS & $15.22 * *$ & $9.87 * *$ & \\
\hline
\end{tabular}

Fig.1 Effect of different seedling categories on germination percentage $(\%)$ of cocoa at $7^{\text {th }}$ and $15^{\text {th }}$ day after sowing

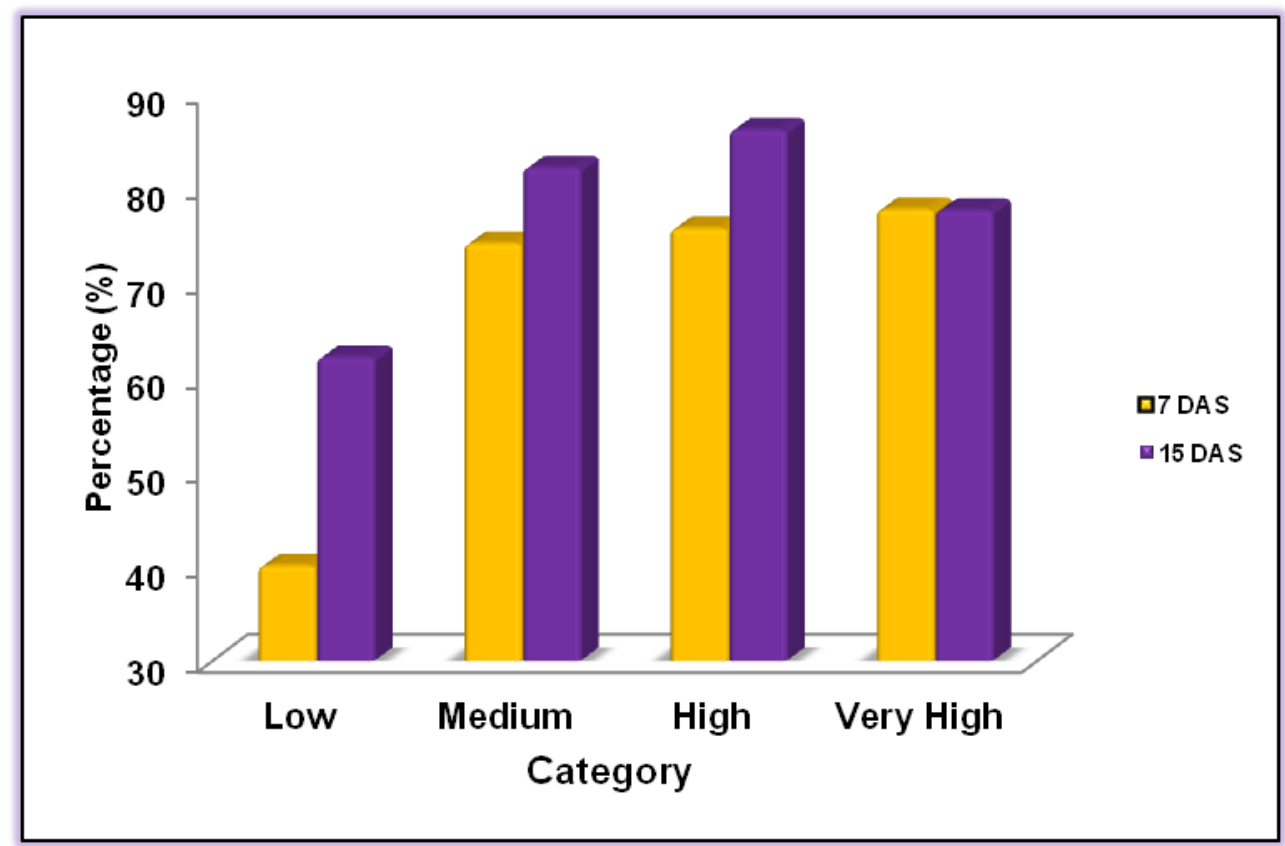

DAS: Days After Sowing 
Fig.2 Seedling vigour at different seedling categories at nursery stages of cocoa

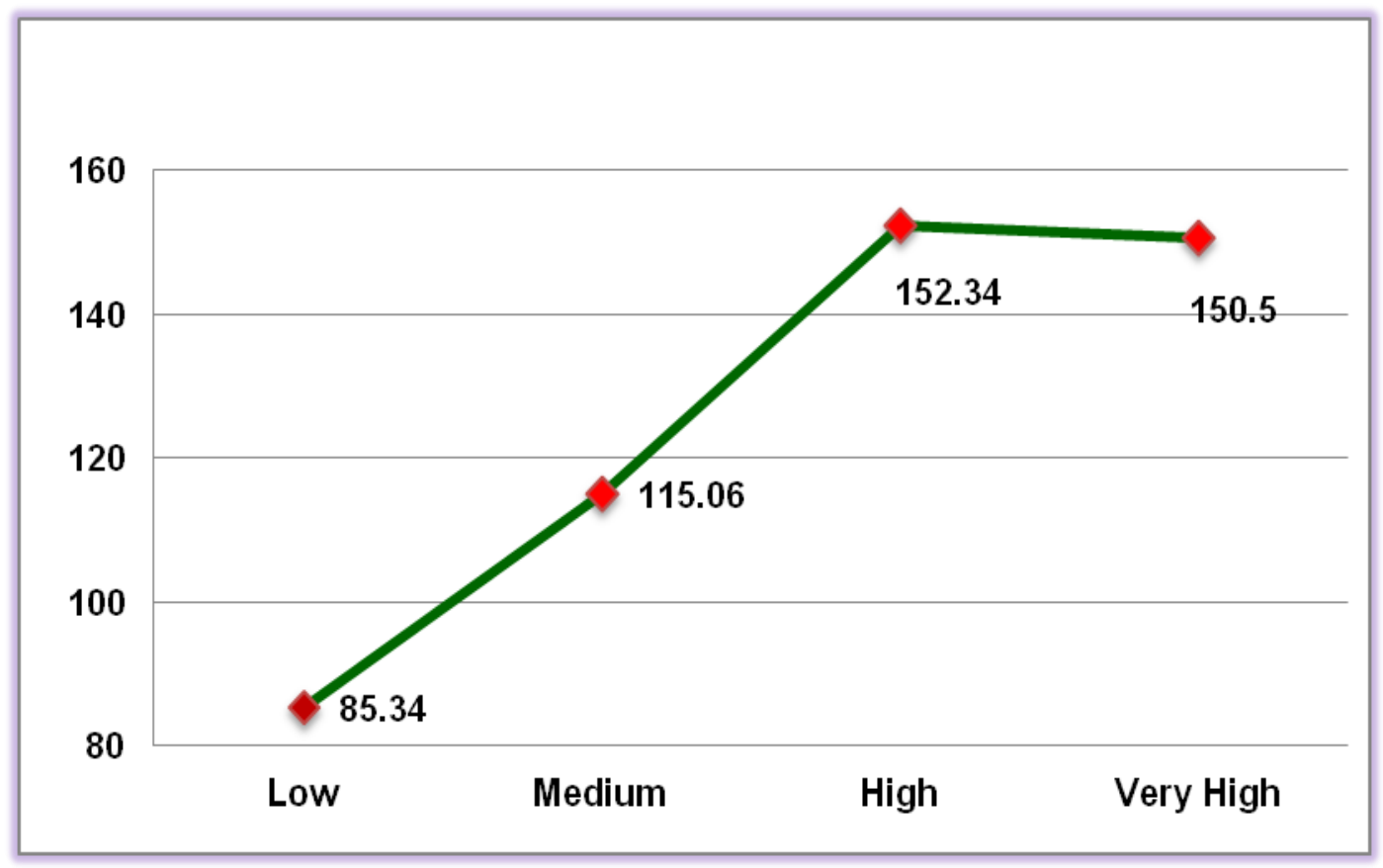

\section{Seedling vigour}

Seedling vigour exhibited significant differences among the different categories of seedlings at all stages of observations. However, at most of the stages, high and very high yielding categories (152.34 and 150.50) remained on par with each other. The low yielding category invariably exhibited poor seedling vigour (85.34) at all stages of growth (Fig. 2). Seedling vigour of cocoa was influenced by varieties (Adenikinju, 1969) and bean maturity at the time of sowing (Adenikinju, 1972, 1974, 1978).

Further, in the present investigation was evident that the seedlings from 'very high' and 'high' yielding groups exhibited better morphological traits in terms of seedling height, number of leaves, girth, internodal length and leaf area per seedlings etc., than 'medium' and 'low' yielding categories of seedlings. This kind of approach when taken up in coconut and arecanut has resulted in ideal seedling selection criteria based on high heritable characters (earliness in germination, seedling height, girth of the seedling etc.

It is concluded, on the basis of the different growth parameters recorded, (germination percentage, seedling height, girth, no of leaves, seedling vigor etc.), it is concluded that seeds from 'high' and 'very high' yielding mother trees are likely to produce vigorous seedlings. The selection based on seedling vigour has to be verified in the field based on yield performance.

\section{Acknowledgment}

The first author is grateful to Department of Spices and Plantation Crops, Horticultural College and Research Institute, Tamil Nadu Agricultural University, Coimbatore for providing necessary facilities to carry out the research work and Cadbury India Ltd. for providing financial assistance for this study. 


\section{References}

Adeninkinju, S.A. 1969. A comparative study of the performance of six different cocoa types. In. Proc. 3rd Int. Cocoa Research Conference Accra 23-29 Nov. 579-583.

Adeninkinju, S.A. 1972. Effect of pod maturity on bean development, viability, mucilage content and seedling vigour in cocoa Expl. Agric. 8, 123-129.

Adeninkinju, S.A. 1974. Analysis of growth patterns on cocoa seedlings as influenced by bean maturity. Expl. Agric. 10, 141 - 147.

Adeninkinju, S.A.1978. The selection of cocoa pods for raising seedlings. Cocoa Growers' Bulletin 27 June 1978, 27 33.

Amma, P. S., Mallika, V. K. Shalini, M. Raji, M. and Nair, V. R. 2002. An insight into the pre selection method in cocoa. In: Proceedings of National seminar on cocoa. CPCRI, Regional Station, Vittal, Karnataka. pp: 52-53.

Ananda, K. S., Rajesh, B. and Shobha, R. 2008. Variation in germination, seedling morphology and bio-chemical traits among indigenous arecanut (Areca catechu L.) accessions. J. Plantation crops, 36(3):166-170.

Ascenso, J. C. and Bartley, B. G. D.1966. Varietal relationships of growth factors of young cacao seedlings. Euphytica, 15:211-222.
Bhagavan, S. and Nair, B. P. 1989. Vigour index as an additional parameter in identifying elite palms in arecanut. J. Plantation Crops, 16 (Supl.,): 389-394.

Bismark, M. B. 2011. Effect of watering regime and cocoa pod husk on soil fertility and growth of hybrid cocoa seedlings in the semi - deciduous forest zone of Ghana. M.Sc. Thesis, Kwame Nkrumah University of Science and Technology, Kumasi.

Liyanage, D.V. 1953. Selection of coconut seed nuts and Seedlings. The Ceylon Coconut, 3 \& 4: 127-129.

Liyanage, D. V. and Abeywardena, V. 1957. Correlations between seednut, seedlings and adult palm characters in coconut. Tropical Agriculture, CXIII (4): 325-40.

N`Goran, J. A. K., Laurent, V. Risterucci, A. M. and Lanaud, C.. 2000. The genetic structure of cocoa populations (Theobroma cacao L.) revealed by RFLP analysis. Euphytica, 115: 83-90.

Panse, V.G. and Sukhatme, P.V. 1967. In: Statistical method for agricultural worker, ICAR Pub, New Delhi

Sahasranaman, K. N.1962. The importance of seed nut selection in coconut cultivation. Coconut bulletin, $10 \& 11$ : $417-421$.

Thondaiman, V. 2011. Studies on genetic diversity and molecular characterization of cocoa (Theobroma cacao L.). Ph.D. (Hort.) Thesis, Tamil Nadu Agricultural University, Coimbatore.

\section{How to cite this article:}

Janani, P., N. Kumar and Jegadeeswari, V. 2018. Standardization of Seedling Selection Criteria in Cocoa (Theobroma cacao L.). Int.J.Curr.Microbiol.App.Sci. 7(12): 856-862. doi: https://doi.org/10.20546/ijcmas.2018.712.106 